\title{
Using Data Envelopment Analysis as a public transport project appraisal tool
}

\author{
Brian Caulfield ${ }^{1}$, Diarmuid Bailey, and Shane Mullarkey \\ Department of Civil, Structural and Environmental Engineering, Trinity College \\ Dublin, Dublin 2, Ireland
}

\begin{abstract}
The provision of a fast, frequent and modern public transport service operating from Dublin city centre to the airport has been a topic of great interest in recent times, in Ireland. Due to Ireland's poor financial situation, the choice of infrastructure investment has become more important than ever and hence, large expensive projects such as an underground Metro line called Metro North have been widely criticised. The main objective of this research is to investigate and identify the most efficient transport solution for the Dublin city centre - airport route. The Dublin Area Rapid Transit (DART) (over ground heavy rail) spur and Metro North are explored along with a Bus Rapid Transit (BRT) route and a Luas (tram) line. Data Envelopment Analysis (DEA) was employed to identify the most efficient solution for the city centre - airport route and to establish the reasons for inefficiency.

The findings of this research indicate that, when costs are included in the analysis, the BRT Airport is the most efficient option for the airport route providing the greatest value for money. Metro North and Luas Airport, at present, do not provide enough transportation benefits to justify their excessive cost over the BRT solution. The DART Spur is found to be the cheapest rail option but also the one with the fewest benefits. The findings and methods used in this research could be used in other public transport investment cases to ascertain the best case for investment and could be used in conjunction to cost benefit analysis. This research adds to the field of implementing DEA in the field of public transport investment analysis. While DEA has been applied to other areas of transport analysis few have compared different investment and mode options on one route.
\end{abstract}

\section{INTRODUCTION AND BACKGROUND}

The following section gives a description of some of the most common transport project appraisal methods. Odgaard et al (2005) indicates that Cost Benefit Analysis (CBA) and Multi Criteria Analysis (MCA) are the two most widely used forms of transport project appraisal in Europe for road and rail projects. In this section, a detailed description will be given of each method including their advantages and disadvantages. Finally, the appraisal method utilised in this research, DEA analysis, is explained. A brief summary at the end attempts to explain why DEA may be a more beneficial tool than both CBA and MCA in project appraisal.

\subsection{Cost Benefit Analysis (CBA)}

CBA is one of the most widely used methods of analysis for transport project appraisal in Europe (Odgaard et al, 2005). Browne \& Ryan (2011) state that CBA

\footnotetext{
${ }^{1}$ Corresponding author: Tel +35318962534; Fax +3531677 3072; email: brian.caulfield@tcd.ie
} 
involves estimating the full direct and indirect private and social costs and benefits associated with a potential project. These costs and benefits are then monetised and the ratio of total benefits to overall cost is examined i.e. the Benefit Cost Ratio (BCR). The BCR value must be greater than 1 for the project to be economically viable, i.e. the overall monetary benefits must be greater than the cost. This provides policymakers with a clear, simple mechanism to decide between alternative projects (Browne \& Ryan, 2011). However, even though CBA is a widely accepted tool in assessing project viability, it also has several limitations. Recent studies (Browne \& Ryan, 2011; Damart \& Roy, 2009; Tudela et al, 2006) have indicated that it is very difficult to monetise all the impacts of transport projects, in particular benefits or costs that do not have constant economic values e.g. air pollution, noise pollution, accidents, travel time, etc. Take travel time as an example, what factors should be taken into account when putting a monetary value on time saved (Geographic zone? Profession? Social status? Travel purposes?). Damart \& Roy (2009) indicate that these values are open to interpretation and bias, and are often misrepresented, leading to unrealistic evaluation of particular benefits and costs. If these effects are not correctly converted to monetary values, then the CBA is not a true realistic account of the viability of the project. In a large infrastructure project such as Metro North environmental benefits such as congestion reduction, emissions reduction, travel time savings, sustainable transport, etc. are critical and so it must be questioned whether a CBA is the correct method of appraisal for these large public transport projects.

\subsection{Multi-criteria Analysis (MCA)}

MCA has appeared as an alternative appraisal method to deal with the limitations of the CBA approach (Tudela et al, 2006). MCA covers a broad range of techniques, however the main difference between MCA and CBA is that the MCA approach can accept qualitative and quantitative parameters and is objectives led whereas CBA only analyses monetised values of costs and benefits (Nijkamp et al, 2002; Tudela et al, 2006). Therefore, MCA avoids the pitfall of evaluating monetary values for impacts that are difficult to ascertain i.e. environmental impacts such as noise pollution, value of life etc. Browne \& Ryan (2011) state that MCA is increasingly being used in transport decision making due to (i) the complexity of the issues involved, (ii) the need to holistically capture environmental, economic and social impacts, and (iii) the inadequacies of conventional tools such as CBA for capturing the full range of impacts of a policy or capital project. Tudela et al (2006) compared the outputs of CBA and MCA when analysing two alternatives in improving part of the road system in the Chiguayante District, Concepcion, Chile. The results found that on a purely economic basis, both the MCA and CBA chose the same alternative. However, when non-economic and environmental benefits were taken into account, the MCA approach chose a different alternative to the CBA. The alternative finally chosen by the authority was the one selected as being the best using the MCA approach including environmental effects. They found that the impacts on the local community were severely underestimated when using the CBA analysis. Tudela et al (2006) suggested that MCA should be used as part of a framework for project appraisal, or at least a combination of CBA and MCA. However, even though MCA is becoming more popular in transport project appraisal, several studies (Browne \& Ryan, 2011; Grant-Muller et al, 2001) have illustrated many issues associated with the use of MCA such as:

- Identifying and defining the impacts to be included. 
- Specifying the measurement method and how each impact will subsequently be assigned a score.

- Issues surrounding the use of weights and how these might be obtained in practice.

- Variations in how the scores and weights are combined to give an overall project score.

\subsection{Data Envelopment Analysis}

DEA is a linear programming based technique that provides an objective assessment of the relative efficiency of similar organizational units (Sarica \& Or, 2007). These organizational units are known as Decision Making Units (DMUs) in DEA analysis i.e. in this research the DMUs are the different transport alternatives (Cooper et al, 2000). These DMUs use a variety of identical inputs to produce identical outputs and DEA analysis attempts to identify the most efficient DMUs and to point out specific inefficiencies in the other DMUs (Ramanathan, 2000; Cook \& Seiford, 2009). DEA reduces a multiple input/output situation to that of a single 'virtual' output and 'virtual input' using calculated weight values assigned to each input/output (Cooper et al, 2004). The ratio of this single virtual output to single virtual input provides a measure of efficiency. The efficiency of each DMU is calculated using frontier analysis, which is demonstrated using a simple example from Cooper et al (2000). DEA has been applied in the transportation field to examine the efficiency of a number of options. Several studies have used the approach to examine the efficiency of airports and airlines (Adler and Berchman, 2001; Barros et al 2010; Barros, 2011 and Oum et al 2005) and the efficiency of public transport services (Vuuren, 2002; Barros and Peypoch, 2010; Lao and Lin, 2009; Odeck, 2008 and Karlaftis, 2004). The methodology section will discuss the DEA approach in greater detail.

\section{METHODOLOGY}

This section of the paper provides detailed background information on the three DEA models utilised as part of the analysis of the different transport solutions for the city centre - airport route. DEA is defined as a method to determine the relative efficiencies of a set of organisational units when there are multiple incommensurate inputs and outputs. The two DEA models used in this paper are the Charnes-CooperRhodes (CCR), Banker-Charnes-Cooper (BCC).

\subsection{The CCR Model}

The CCR model is one of the most basic DEA models (Cooper et al 2000). There is a significant amount of research (Cooper et al, 2000; Cook \& Seiford, 2009; Cooper et al, 2004) which describes the mathematical background to the basic CCR model, and the following description is adapted from these sources. Consider a set of $\mathrm{n}$ DMUs, with each DMU $\mathrm{j},(\mathrm{j}=1, \ldots, \mathrm{n})$ using $\mathrm{m}$ inputs $x_{i j}(\mathrm{i}=1, \ldots, \mathrm{m})$ and generating $\mathrm{s}$ outputs $y_{r j}(\mathrm{r}=1, \ldots, \mathrm{s})$. The following fractional programming problem is to be solved to obtain values for the input weights $\left(v_{i}\right)(\mathrm{i}=1, \ldots \ldots, \mathrm{m})$ and the output weights $\left(u_{r}\right)(\mathrm{r}=1, \ldots, \mathrm{s})$ : 


$$
\begin{aligned}
e_{o}=\max & \sum_{r} u_{r} y_{r o} / \sum_{i} v_{i} x_{i o} \\
\text { s.t. } & \sum_{r} u_{r} y_{r j}-\sum_{i} v_{i} x_{i j} \leqslant 0, \quad \text { all } j \\
& u_{r}, v_{i} \geqslant \varepsilon, \quad \text { all } r, i .
\end{aligned}
$$

Equation 1

The constraints mean that the ratio of virtual output to virtual input should not be greater than 1 for every DMU, and $\varepsilon$ is a non-archimedian value designed to enforce strict positivity on the variables. The above fractional programming problem can be replaced by the following equivalent linear programming problem using the CharnesCooper Transformation (for more information see Charnes \& Cooper (1962)) $\left(L P_{O}\right)$ :

$$
\begin{aligned}
e_{0}=\max & \sum_{r} \mu_{r} y_{r o} \\
\text { s.t. } & \sum_{i} v_{i} x_{i o}=1 \\
& \sum_{r} \mu_{r} y_{r j}-\sum_{i} v_{i} x_{i j} \leqslant 0, \quad \forall j \\
& \mu_{r}, v_{i} \geqslant \varepsilon, \quad \text { all } r, i .
\end{aligned}
$$

Equation 2

By duality, this problem is equivalent to the dual linear programming problem $\left(D L P_{O}\right)$ :

$$
\begin{aligned}
& \min \theta-\varepsilon\left(\sum_{i=1}^{m} s_{i}^{-}+\sum_{r=1}^{s} s_{r}^{+}\right) \\
& \text {subject to } \\
& \sum_{j=1}^{n} x_{i j} \lambda_{j}+s_{i}^{-}=\theta x_{i o} \quad i=1,2, \ldots, m ; \\
& \sum_{j=1}^{n} y_{r j} \lambda_{j}-s_{i}^{+}=y_{r o} \quad r=1,2, \ldots, s ; \\
& \lambda_{j}, s_{i}^{-}, s_{r}^{+} \geq 0 \forall i, j, r
\end{aligned}
$$

\section{Equation 3}

Where $s^{-}$are the input excesses and $s^{+}$are the output shortfalls and, by the duality theorem $^{2}$ of linear programming, the optimal objective value of $L P_{O}\left(e_{0}^{*}\right)$ is equal to the optimal objective value of $D L P_{O}\left(\theta^{*}\right)$. This problem can be solved in 2 stages. First the solution of $\theta^{*}$ must be found by solving:

\footnotetext{
${ }^{2}$ Duality Theorem: (i) In a primal-dual pair of linear programmings, if either the primal or the dual problem has an optimal solution, then the other does also, and the two optimal objective values are equal.

(ii) If either the primal or the dual problem has an unbounded solution, then the other has no feasible solution.

(iii) If either problem has no solution then the other problem either has no solution or its solution is unbounded (Cooper et al, 2000).
} 


$$
\begin{aligned}
& \theta^{*}=\min \theta \\
& \text { subject to } \\
& \sum_{j=1}^{n} x_{i j} \lambda_{j} \leq \theta x_{i o} \quad i=1,2, \ldots, m \text {; } \\
& \sum_{j=1}^{n} y_{r j} \lambda_{j} \geq y_{r o} \quad r=1,2, \ldots, s \text {; } \\
& \lambda_{j} \geq 0 \quad j=1,2, \ldots, n \text {. Equation } 4
\end{aligned}
$$

The next step is to fix $\theta=\theta^{*}$ and find a solution that maximises the sum of the input excesses and output shortfalls.

$$
\begin{aligned}
& \max \sum_{i=1}^{m} s_{i}^{-}+\sum_{r=1}^{s} s_{r}^{+} \\
& \text {subject to } \\
& \sum_{j=1}^{n} x_{i j} \lambda_{j}+s_{i}^{-}=\theta^{*} x_{i o} \quad i=1,2, \ldots, m ; \\
& \sum_{j=1}^{n} y_{r j} \lambda_{j}-s_{r}^{+}=y_{r o} \quad r=1,2, \ldots, s ; \\
& \lambda_{j}, s_{i}^{-}, s_{r}^{+} \geq 0 \forall i, j, r
\end{aligned}
$$

\section{Equation 5}

Now the performance of a DMU is said to be fully (100\%) efficient if, and only if, both (i) $\theta^{*}=1$ and (ii) all slacks ${s_{i}}^{-{ }^{*}}={s_{r}}^{{ }^{*}}=0$. The DMU is weakly efficient if, and only if, (i) $\theta^{*}=1$ and (ii) ${s_{i}}^{-^{*}} \neq 0$ and/or ${s_{r}}^{+^{*}} \neq 0$ for some $i$ and $r$ (Cooper et al, 2000; Cooper et al, 2004). One of the main assumptions of the CCR model is constant returns to scale, i.e. there are no scale effects, if the inputs are increased by $\mathrm{m}$ then the outputs will also be increased by m (Sarica \& Or, 2007). This is a big assumption, however, in the next section the BCC model will be examined, which allows variable returns to scale. The CCR and many other DEA models can be input orientated or output orientated. Input orientated attempts to reduce inputs by as much as possible while at least keeping the present level of outputs (Cooper et al, 2000). Output orientated maximises output levels using at most the present input consumption (Cooper et al, 2000).

\subsection{BCC Model}

The BCC model is an extension of the CCR model, which investigates variable returns to scale. The following mathematical formulae for the BCC model are quite similar to that of the CCR model, except for an additional variable $u_{0}$ and are outlined in Cook \& Seiford (2009) and Cooper et al (2000). 


$$
\begin{aligned}
e_{o}^{*}=\max & {\left[\sum_{r} u_{r} y_{r o}-u_{o}\right] / \sum_{i} v_{i} x_{i o} } \\
\text { s.t. } & \sum_{\mathrm{r}} u_{\mathrm{r}} y_{r j}-u_{o}-\sum_{i} v_{i} x_{i j} \leqslant 0, \quad j=1, \ldots, n \\
& u_{r} \geqslant \varepsilon, \quad v_{i} \geqslant \varepsilon, \quad \forall i, r \\
& u_{o} \text { unrestricted in sign. }
\end{aligned}
$$

\section{Equation 6}

The linear programming equivalent is (similar to CCR):

$$
\begin{aligned}
e_{o}^{*}=\max & \sum_{r} \mu_{r} y_{r o}-\mu_{o} \\
\text { s.t. } & \sum_{\mathrm{i}} v_{\mathrm{i}} x_{i o}=1 \\
& \sum_{r} \mu_{r} y_{r j}-\mu_{o}-\sum_{i} v_{i} x_{i j} \leqslant 0, \quad j=1, \ldots, n \\
& \mu_{r} \geqslant \varepsilon, \quad v_{i} \geqslant \varepsilon, \quad \forall i, r, \quad \mu_{o} \text { unrestricted. Equation 7 }
\end{aligned}
$$

Again, similar to the CCR model seen previously, this is equivalent to the following dual linear program.

$$
\begin{array}{ll}
\min & \theta-\varepsilon\left(\sum_{i} s_{i}^{-}+\sum_{r} s_{r}^{+}\right) \\
\text {s.t. } & \sum_{j} \lambda_{j} x_{i j}+s_{i}^{-}=\theta_{o} x_{i o}, \quad i=1, \ldots, m \\
& \sum_{j} \lambda_{j} y_{r o}-s_{r}^{+}=y_{r o}, \quad r=1, \ldots, s . \\
& \sum_{j} \lambda_{j}=1 \\
& \lambda_{j}, s_{i}^{-}, s_{r}^{+} \geqslant 0 \quad \forall i, r, j \\
& \theta \text { unrestricted. }
\end{array}
$$

\section{Equation 8}

As with the CCR approach, this problem is solved in two phases. The $1^{\text {st }}$ step is to minimise $\theta$ to find $\theta^{*}$. The $2^{\text {nd }}$ step is to keep $\theta=\theta^{*}$ and maximise the sum of the input excesses and the output shortfalls. The other major difference between the two models is the extra constraint, $\sum_{j} \lambda_{j}=1$, in the BCC model. This ensures that the feasible region for the BCC model is a subset of that of the CCR model, and so, any CCR-efficient DMU is also BCC efficient (Cooper et al, 2000; Cook \& Seiford, 2009). Again, similar to the CCR model, a DMU is said to be BCC efficient if, and only if, both (i) $\theta^{*}=1$ and (ii) all slacks ${s_{i}}^{-^{*}}={s_{r}}^{+^{*}}=0$ (Cooper et al, 2000; Cook \& Seiford, 2009).

Both the CCR and the BCC models have been estimated in this paper. While the authors acknowledge the heavy assumptions of constant returns to scale of the CCR model. It is necessary to include this model to build towards the BCC model. Several other authors have used this approach in the evaluation of public transport systems 
and services (Coelli and Perelman, 1999; Chiou et al, 2012; Hirschhausen and Cullmann, 2010).

\section{TRANSPORT OPTIONS CONSIDERED}

The following section outlines in detail the main transport solutions proposed for the city centre to Dublin airport route. These options represent the DMU's which were analysed using DEA software. Information is provided on the route descriptions, method of route selection, operational characteristics and line attributes as entered into the four-stage transport model. Tables 1 and 2 present the results from the modelling work done on the different options considered. A SATURN based fourstage modelling approach was used to estimate these values. This four-stage modelling was conducted as conducted in co-operation with the National Transport Authority of Ireland. National Transport Authority (2010) provides full details of the modelling approach used in the four-stage model. Please see Ortuzar and Willumsen (2011) for more information on the four-stage model.

When defining the routes to be examined the authors examined the physical space and the requirements for each of the routes. The new routes considered (those not part of any previous National Transport Authority plans) were the light rail and BRT options. The BRT option uses a traffic tunnel and a motorway to reach the airport, this explains why there is a lack of stops on this option. The light rail option follows a path to the airport that enables it to serve all of the major trip generators on route to the airport.

\subsection{Existing Bus Routes}

There are a number of bus routes, which currently serve Dublin airport. These are analysed as the base scenario to identify what transportation benefits (if any) introducing new infrastructure will have. Two current Dublin Bus routes were chosen to represent the status quo and these are the number 16 and number 41 routes. The line attributes of the current number 16 and number 41 routes as coded in the NTA model are outlined in Table 1. Column 2 contains the headway for each route, i.e. the amount of time between the departures of buses. Column 3 displays the length of each route, while column 4 and 5 display the number of seats on the vehicle and the overall crush capacity (total number of possible seated and standing passengers). The final column illustrates the average speeds of the buses on the route (in kilometres per hour $(\mathrm{km} / \mathrm{h}))$. Table 2 details the results from the model run conducted on the transport options considered.

\subsection{Metro North}

The proposed Metro North route is $16.5 \mathrm{~km}$ long from the airport to the city centre. There are 14 stops planned along the route, including 9 underground and 5 at ground level (RPA, 2010). Services will run every 5 minutes at peak when the system opens, which can be increased to allow services to run every 2 minutes as demand increases, serving a capacity of 20,000 ppdph (RPA, 2010). Tables 1 and 2 provide a detailed explanation of the Metro North route as coded in the NTA transport model. Metro North uses vehicles with a seating capacity of 212 people and an overall crush capacity of 705. The speeds of the system are factored in the NTA model to include station dwell times. Figure 1 details the catchment area of the Metro North option. 
Table 2 also shows that the Metro North option would result in the largest number of highway trips removed.

\section{$<<$ INSERT FIG 1 $>$}

\subsection{DART Spur}

The Dublin Area Rapid Transit system (DART) is heavy rail network that operates services in Dublin. This option consists of building a new spur from the current DART network to the Airport. The route was examined with headways of 30 minutes and services the same stops throughout the city (see Table 2). Figure 2 shows the catchment area of this option. The results in Table 2 show that the DART option has a predicted travel time of 34 minutes and if constructed would result in a modest reduction in highway trips removed.

\section{$<$ INSERT FIG 2>>}

\subsection{Luas Alternative}

Luas is a tram network that operates in Dublin. This Luas option would see an extension of the light rail network to the airport. Tables 1 and 2 detail the model results from the Luas option. The catchment area for the Luas option can be seen in Figure 3. The results for the light rail option show a 25 minute travel time and after Metro North it would result in the largest number of highway trips removed (see Table 2).

\section{$<<$ INSERT FIG 3 $>$}

\subsection{BRT Alternative}

The final option considered is the BRT option to the airport. This option would utilise the Dublin Port Tunnel and join the motorway to the airport from this tunnel. Using the Port Tunnel would result in substantially reduced bus travel times to the airport of approx. 13 minutes compared to the longer running times of the current bus routes in the city (see Table 2). The catchment area of the BRT is less than that of the other options as the route travels though a low-density area and uses a tunnel and the ring motorway (see Figure 4).

\section{$<$ INSERT FIG 4 >}

$<$ INSERT TABLE 1 >

$<$ INSERT TABLE 2>>

\section{DEA MODEL RESULTS}

\subsection{Selecting Model Inputs and Outputs}

To access the options considered in this research, a number of DMUs need to be defined. The DMUs in this research are taken as the different transport solutions considered for the Dublin city centre - airport route. These are the 16, 41, Metro North, BRT Airport, Luas Airport and DART Spur. This relatively small number of DMUs applies a constraint on the number of inputs and outputs that can be used in the DEA model. Cooper et al (2000) state that if the number of DMUs is less than the 
combined number of inputs and outputs, a large portion of the DMUs will be identified as efficient and discrimination will be lost. Hence, it is suggested that the number of DMUs be at minimum equal to the sum of inputs and outputs. Therefore, in this research 1 input and 3 outputs were used in the DEA model. It was decided that the DEA model would run similarly to a CBA, however, without the associated pitfalls mentioned in the literature review section, i.e. applying monetary values to transportation impacts which do not have constant economic values. The DMU's used in the proceeding models include; travel time-savings, patronage, car trips removed and cost.

\subsubsection{Travel Time savings}

This is the overall time saved per trip from the city centre to the airport, due to the implementation of each new transport solution measured in minutes. The values for travel time saved for each DMU were calculated from the NTA transport model results (see Table 2) and are presented in Table 3.

\subsubsection{Patronage}

Patronage refers to the actual number of people using each alternative transport service to the airport. It is measured in 100,000 s of passengers. The patronage for each DMU for the 3-hour am-peak was taken directly from the results of the fourstage model analysis (Table 2) and multiplied by 215 (average number of working days in the year) to calculate the total number of people that use each service within the am-peak each year. This time period was chosen, as it is the busiest time on the transportation network. While one could argue that this isn't the peak travel time to the airport, airport traffic on each of the routes constitutes approximately $20 \%$ of all passenger trips along the route. The results are presented in Table 3.

\subsubsection{Car Trips Removed}

Car Trips Removed represents the number of additional car trips taken off the road for the 3-hour am-peak due to the implementation of each transport option. A reduction in car trips on the road network should lead to a reduction in greenhouse gas emissions, accidents and reduced traffic congestion, which will allow significant nonuser time savings. The base case was assumed to be the current transportation network including all public transport options available at present in the GDA. The number of car trips removed for the am-peak is measured in 10,000s of trips. These were multiplied first by 2 (return trip), to represent the removal of their return trips, and then by 215 (number of working days in year), to calculate the overall number of trips removed for the am-peak each year. The results are presented in Table 3.

\subsubsection{Cost}

The overall cost of implementing each transportation system was taken as the single input in the DEA model. This included both capital costs, and vehicle operating and maintenance (O\&M) costs for a typical 30 year design period. Due to the sensitive nature of cost estimates for projects such as Metro North and the DART Spur, actual prices for each transport solution could not be obtained. Therefore, both capital and O\&M costs were estimated from studies of different systems worldwide.

\section{(i) Capital Cost}


The capital cost refers to the initial cost to set up each system, i.e. infrastructure costs, construction costs, vehicle costs, station costs etc. and the estimated value for each DMU is outlined in the following section.

Route 16 and 41: As the current bus network is already in place, it was assumed that the capital cost for both route 41 and route 16 would be zero.

DART Spur: The business case for the DART Spur option put the cost of this option in the region of $€ 200$ million (Irish Times, 2011a).

Luas Airport: It was assumed that the cost of the new Luas system to the airport would be similar to the current Green and Red Lines already in place. Studies by Dunny \& Caulfield (2010) and Leahy (2010) indicate that the capital cost of the Luas in Dublin was approximately $€ 32$ million per $\mathrm{km}$. Therefore, the overall cost of the new proposed system was calculated to be €363.2 million in $2009 €$ 's.

BRT Airport: The capital cost of the new proposed BRT route was evaluated from information provided by the TRB's BRT Practitioner's Guide on existing systems worldwide (TCRP, 2007). The overall capital cost was broken down into four main sections; Busway, Transit Signal Priority, Stations and Vehicles. Based upon the international examples and the details of the proposed BRT system a cost of $€ 61$ million was estimated.

Metro North: As the RPA will not release estimated cost figures for Metro North due to the current on-going tendering process, a number of ranging values have been suggested in various newspaper articles and reports. Irish Times (2011b) indicates that the cost figures varying from $€ 2.5$ billion to $€ 5$ billion. The cost used in this study was $€ 2.5$ billion.

(ii) $O \& M$ Costs

Similar to capital costs, the O\&M costs had to be estimated from relevant experience and studies performed worldwide. The O\&M costs for the Luas Airport alternative were calculated from the final business case for the Luas $\mathrm{C} 1$ extension to the Point Village. In this document, the RPA state that the expected O\&M costs for the 30 year operating period would be $€ 46.1$ million (2006 $€ \mathrm{~s})$ (RPA, 2007). Therefore, to obtain an approximation on O\&M costs/ $\mathrm{km} /$ year, this overall value was divided by 30 , and then, by the length of the line $(1.5 \mathrm{~km})$. This provided a value for the Luas of $€ 1.02$ million/km/year. Values of O\&M costs for the other transport solutions were calculated using comparisons made by Hidalgo (2005) on costs for different transit options.

\section{$<$ INSERT TABLE 3 $>$}

\subsection{Efficiency Score Analysis}

The CCR-O score measures the overall efficiency (global efficiency) for each DMU by aggregating pure technical efficiency and scale efficiency into one value (Barros \& Peypoch, 2008). The BCC-O score on the other hand simply measures local pure technical efficiency, i.e. how efficiently the DMU is operating neglecting scale effects (Cooper et al, 2000). 
The inputs and outputs examined in each of the different route options were as follows:

- Outputs:

○ Number of car trips removed

○ Patronage

○ Travel time saving

- Inputs:

○ Cost: Construction costs and operation and maintenance costs

Table 4 provides a detailed description of both the CCR-O and BCC-O model scores for the different cost estimates for Metro North. The BRT and DART Spur are both calculated to be the most efficient solutions for the airport route when analysing CCR scores (global efficiency). The Luas is evaluated as being the $3^{\text {rd }}$ most efficient, with a global efficiency of $83 \%$. The BRT and DART Spur are the transport solutions most frequently referenced for evaluating inefficient DMUs, which further implies that these are the best performing options. When interpreting BCC scores, the 4 proposed transport solutions all become $100 \%$ efficient. The BRT Airport and DART Spur are fully efficient, with both CCR and BCC scores of $100 \%$. Hence, these two transport solutions are operating at optimal operating performance.

The scale efficiency score can be utilised to infer whether certain DMUs are inefficient due to scale size or inefficient operations. For example, Route 16 has a low BCC score and a high scale efficiency among the group, meaning that the overall global inefficiency $(50 \%)$ is caused by inefficient operations rather than scale effects (Cooper et al, 2000). Metro North and Luas Airport both have a high BCC score $(100 \%)$ and relatively low scale efficiency (66\% and $83 \%$ respectively), which suggests that their global inefficiency is due to their scale size. This, combined with the fact that these two solutions display decreasing returns to scale, indicates that they have considerable scope for improvements in their efficiencies by resizing (downsizing) their scales of operations to the optimal scale defined by more productive transport options (BRT Airport, DART Spur) (Thakur et al, 2006). Therefore, it can be said that to become as efficient as the BRT or DART Spur solution both Metro North and Luas Airport would be required to downsize their operations by possibly reducing costs, infrastructure size etc.

\section{<INSERT TABLE 4 >}

\subsection{Slack Analysis}

One of the main conditions for a DMU to be CCR and BCC efficient is that all slacks for that DMU are zero (Cooper et al, 2000; Charnes et al, 1978). The presence of slacks indicates that it may be possible to decrease inputs or increase outputs without effecting efficiency (Charnes et al, 1978). The CCR and BCC slacks are presented in Tables 5 and 6. It is observed that the slacks for BRT Airport and DART Spur are zero, and therefore, it can be said that these DMUs are fully CCR efficient. Likewise, in the BCC model, the slacks for the 4 efficient DMUs are all zero, and hence, they are fully BCC efficient. The slacks represent how much the outputs need to be increased before they come to have positive weights, and hence, contribute to improving efficiencies (Cooper et al, 2000). For example, in CCR analysis, Metro North would be required to have an increase in Travel Time Saving of 97.63 minutes (per trip from the city centre to airport) before affecting its overall efficiency. This 
Travel Time Saving is measured against the base scenario, which includes current transport infrastructure. Therefore, this increase could be obtained due to further future traffic congestion, which considerably increases travel times for the current bus network, or faster Metro travel speeds, with reduced station dwell times due to improved passenger loading and fare collection systems. Likewise, Route 16 would require an increase in Travel Time Saving (per trip from the city centre to airport) of over 35.22 minutes and an increase in Car Trips Removed (per am-peak per year) of over 16,110 trips, before having an effect on improving its overall efficiency.

\section{$<$ INSERT TABLE 5 $>$}

\section{$\ll$ INSERT TABLE 6>>}

\subsection{Projecting onto Efficiency Frontier}

Efficiency frontier analysis solver enables one to identify how each DMU may be moved onto the efficiency frontier. This was examined for the CCR-O model, as it was required to estimate how each DMU could be altered so that it would be performing at its optimal performance. The output CCR model is concerned with maximising outputs with, at most, the given input consumption (Cooper et al, 2007). Therefore, the projections from the CCR-O model indicate by what amount the outputs for each DMU must be changed to achieve efficiency with the given level of cost. Table 7 illustrates the projections of the inefficient DMUs onto the efficiency frontier for the $€ 2.5$ bn Metro North case. The second column in Table 7 describes the current level of inputs and outputs for each DMU. The third column indicates the required level of each input/output needed for it to be operating at its most productive scale size (MPSS), while the final two columns illustrate what increases/decreases are required in each input/output for the DMU to be operating efficiently. The values in these two columns remain zero for the cost input of each DMU due to the fact that the model is output orientated. The percentage increase in Patronage and Car Trips Removed for Metro North to be operating at its MPSS are constant at $51.25 \%$. However, the value for Travel Time Saving is significantly higher (about four times) due to the presence of slacks, which indicates that this output is a particular weakness for Metro North over its efficient alternatives (BRT, DART Spur). As mentioned previously, the slack analysis indicates that Travel Time Saving for Metro North would need to increase by 97.63 minutes/trip to start having an effect on efficiency. If this value is subtracted from the projection value for travel time saving, the new percentage increase required would equal approximately $51.25 \%$, similar to the other two outputs. This simple calculation illustrates the effect that slack values have on the projection results. Therefore, it can be concluded that Travel Time Saving is the most important transportation benefit that needs improvement for Metro North to be operating efficiently at its given level of cost. Obviously, this increased Travel Time Saving of 110.9 minutes/trip (approximately 1.85 hours/trip) over the current bus network is almost impossible to achieve, unless there is a significant increase in traffic congestion, which intensifies bus travel delay.

The projections for the other two outputs are quite excessive also, with an extra Patronage required of 2,295,000 passengers/am-peak/year, and the necessary removal of an additional 324,800 car trips from the network for the systems to be worth its substantial costs. It is evident that Metro North is unlikely to reach these significant output targets in the near future, and hence, would be required to vastly 
reduce its cost value to become efficient. However, further down the line, if no major improvements in the public transport network are introduced and population and car traffic continue to grow, there are likely to be massive congestion problems within Dublin city which will effect car and bus travel. Similar analysis can be made for the Luas Airport alternative. Again, it's Travel Time Saving projection is substantially larger than it's other two outputs due to the presence of slacks, indicating that this is a particular weakness for the Luas solution. It is clear that the projection values required for Luas Airport to be operating efficiently are much less than those for Metro North, predominantly due to the fact that it costs less than one third its price. However, even though its projection values are far less than Metro, its outputs still would need to be significantly improved due to traffic congestion and traffic management policies in the future for the system to be efficient and viable at its present cost estimate. The BRT Airport and DART Spur both have equal original and projection data values in Table 7, illustrating the fact that these two solutions are on the efficiency frontier and are, hence, operating at their MPSS.

\section{$<<$ INSERT TABLE 7 $>>$}

\subsection{Sensitivity Analysis}

Sensitivity analysis is an extremely important attribute of DEA to evaluate the robustness of the results obtained. Numerous approaches to sensitivity analysis of DEA are available in the literature (Jha, 2006). Sensitivity is defined as the effect on DEA efficiency upon inclusion or exclusion of one or more variables from the model and not with respect to parametric variation of input or output variables (Pahwa, 2002). The present approach assumes that the data set is correct and precise and removes individual variables one by one to observe differences in the DEA efficiencies (if any), thereby checking the robustness of the base model DEA results obtained. Note: upon removal of a variable, the efficiency score will either remain unchanged or decrease but never will it increase. On the basis of sensitivity analysis, divisions have been classified into different categories (Pahwa, 2002, Jha, 2006).

The following terms are used to describe how efficient the DEA model is when some of the DMUs are removed. Table 8 presents the findings of the sensitivity analysis.

- Robustly efficient: The DEA efficiency level at 1 or slightly below 1 , when the variables are removed one at a time.

- Marginally efficient: The efficiency is 1 for the base model and remains at one in some situations, but drops significantly in other situations.

- Marginally inefficient: The DEA efficiency is below 1 but above 0.9 for the base model and stays within that range for sensitivity analysis.

- Significantly inefficiently: The DEA efficiency is between 1 and 0.9 and drops to a much lower value during sensitivity analysis.

- Distinctly inefficient: The DEA efficiency is below 0.9 in all the conditions

The purpose of the analysis presented in Table 8 is to show that the models estimated in this research are robust in that if some of the variables are omitted from the models that it doesn't impact upon the overall efficiency score of the mode of transport. The results presented in Table 8 shows that each of the models are robust, demonstrating that the model specifications are representative and that the over all efficiency scores are not dependent of one variable. 


\section{$<$ INSERT TABLE 8 >}

\section{Policy Implications}

The research presented in this paper shows a traditional public transport investment problem and uses a proven method of comparison to compare the benefits and costs of each of the modes and routes examined. One of the main motivations for conducting this research was a perceived lack of comparison between options when policymakers in Dublin were examining alternative public transport investments options from the city centre to the airport. The research was conducted using the information that was available from several sources and analysing two new route options.

The approach presented demonstrates a method of examining several options in comparison and using the slacks analysis shows how far away from an efficient solution some options are. The flexibly of the DEA to compare and contrast options based upon the inputs and outputs is a strength the approach has over alternatives such as CBA and MCA. The lessons that can be learnt from the case presented in this paper relate to the ability of DEA to provide a framework within which many alternatives can be examined. Within the context of increase scarce public finances and the need to demonstrate value for money, DEA can be used as a framework to examine multiple options and provide policymakers a clear method to examine the merits of alternatives using the same inputs and outputs under one approach. This enables DEA to be used as a complementary tool to CBA and MCA.

\section{Conclusions}

The approach presented in this paper adds to the field transport investment analysis. The findings presented show how the DEA methodology can be used to compare different modes of public transport. The DEA analysis conducted in this research allowed the determination of the most efficient solutions for the airport route. The following conclusions can be derived from the analysis:

- The BRT and DART Spur are the two most efficient solutions operating at their MPSS.

- The Luas Airport and Metro North appear to be inefficient due to their scale size and have considerable scope for improvement in efficiency by downsizing their operations to the optimal scale defined by the BRT and DART Spur i.e. reducing costs, size of infrastructure etc.

- Metro North is calculated to be the least efficient solution predominantly due to its excessive cost. It requires significant improvements in its transportation benefits for it to be operating at its MPSS, and therefore, at present, Metro North does not provide enough benefits to justify its massive cost. However, in the future, if there are no improvements in Dublin's transport network, growing congestion along with the introduction of strategies and policies that favour the use of public transport may increase Metro North's benefits significantly, justifying its extra expense.

- Luas would also require significant future traffic congestion along with public transport incentives to improve its transportation benefits so that it can be 
operating at its MPSS, and therefore, justify its additional cost over the two efficient solutions.

- Sensitivity analysis indicates that the BRT Airport is the only option that is robustly efficient i.e. efficient independent of the presence of particular outputs. The DART Spur is marginally efficient with the number of car trips removed being a particular strength of this solution.

DEA analysis had limited application in Ireland (and internationally) instead of the traditional combination of CBA and MCA as part of transport project appraisal. This research utilised DEA for this purpose, as the literature suggests that it provides numerous benefits over these two most commonly used appraisal techniques. The results presented also show DEA can be used as a powerful decision making tool for similar transport investment options.

\section{Acknowledgments}

The authors wish to thank the National Transport Authority for their assistance in undertaking this research. The authors would also like to thank the reviewers for their helpful comments.

\section{References:}

Adler, N., Berchman, J. (2001) 'Measuring airport quality from the airlines viewpoint: an application of data envelopment analysis'. Transport Policy, Volume 8, Issue 3, Pages 171-181

Barros, C., Managi, S., Yoshida, Y. (2010) 'Productivity growth and biased technological change in Japanese airports'. Transport Policy, Volume 17, Issue 4, pp 259-265

Barros, C. Cost efficiency of African airports using a finite mixture model. Transport Policy, Volume 18, Issue 6, November 2011, pp 807-813

Barros, C.P., \& Peypoch, N. (2008) 'Technical Efficiency of Thermoelectric Power Plants'. Energy Economics, 30, pp 3118-3127.

Barros, C., Peypoch, N. (2010) 'Productivity changes in Portuguese bus companies'. Transport Policy, Volume 17, Issue 5, pp 295-302

Browne, D., Ryan, L. (2011) 'Comparative analysis of evaluation techniques for transport policies'. Environmental Impact Assessment Review, Volume 31, Issue 3, pp 226-233.

Coelli, T., Perelman, S. (1999) 'A comparison of parametric and non-parametric distance functions: With application to European railways.' European Journal of Operational Research, 17, pp 326-339.

Cooper, W.W., Seiford, L.M.,Tone, K. (2000) Data Envelopment Analysis: A comprehensive Text with Models, Applications, References and DEA - Solver Software, Kluwer Academic Publishers, The Netherlands. 
Cooper, W.W., Seiford, L.M., Zhu, J. (2004) Data Envelopment Analysis. Kluwer Academic Publishers, Boston.

Cook, W. D., Seiford, L. M. (2009) 'Data envelopment analysis (DEA) - Thirty years on' European Journal of Operational Research. 192, (1) pp 1- 17.

Chiou, Y.C., Lan, W.L., Yen, B.T.H. (2012) 'Route-based data envelopment analysis models'. Transportation Research Part E. pp 415-425.

Chu, X, Fielding, G, Lamar, B. (1992) 'Measuring transit performance using data envelopment analysis'. Transportation Research Part A: Policy and Practice, Volume 26, Issue 3, pp 223-230.

Damart, S., Roy, B. (2009) 'The uses of cost-benefit analysis in public transportation decision making in France'. Transport Policy, Vol 16, 4, pp 200-212

Dunny, S. \& Caulfield, B. (2010). 'An Examination of the Feasibility of LRT or BRT in Galway' paper presented at the Irish Transport Research Network Conference, $31^{\text {st }}$ August $-1^{\text {st }}$ September 2010.

Hidalgo, D. (2005). "Comparing transit alternatives after recent developments in BRT in Latin America". Paper presented at the January 2005 Transportation Research Board Annual Meeting, Washington DC.

Hirschhausen, V.C., Cullmann, A. (2010) 'A nonparametric efficiency analysis of German public transport companies'. Transportation Research Part E, pp 436-445.

Irish Times (2011a) Accessed on line: http://www.irishtimes.com/newspaper/opinion/2011/0903/1224303421999.html

Irish Times. (2011b), 'Costly Metro North finally hits buffers', Irish Independent, 24 July [online]. Available at: http://www.independent.ie/national-news/costly-metronorth-finally-hits-buffers-2829945.html

Jha, D. K., Yorino, N., Zoka, Y. (2006). Evaluating Performance of Electricity Generating plants using Data Envelopment Analysis: a case study of Nepal. Joint technical meeting on Power Engineering and Power Systems, IEE Japan.

Karlaftis, M. (2004) A DEA approach for evaluating the efficiency and effectiveness of transit systems. European Journal of Operational Research, Volume 152, Issue 2, pp 354-364.

Leahy, J. (2010). "Bus Rapid Transit and Light Rail Transit Investment Alternatives for Dublin: A Case Study of the Lucan Corridor." paper presented at the Irish Transport Research Network Conference, $31^{\text {st }}$ August $-1^{\text {st }}$ September 2010. 
Lao, Y., Lin, L. (2009) 'Performance evaluation of bus lines with data envelopment analysis and geographic information systems'. Computers, Environment and Urban Systems, Volume 33, Issue 4, pp 247-255.

National Transport Authority. (2010) Greater Dublin Area Draft Transport Strategy: 2011-2030. Vision 2030. National Transport Authority, Dublin.

Nijkamp, P., Ubbels, B. \& Verhoef, E. (2002) 'Transport Investment Appraisal and the Environment', Tinbergen Institute Discussion Paper TI 2002-104/3

Odeck, J. (2008) 'The effect of mergers on efficiency and productivity of public transport services'. Transportation Research Part A: Policy and Practice, Volume 42, Issue 4, pp 696-708.

Odgaard, T., Kelly, C., Laird, J. (2005) 'Current practice in project appraisal in Europe'. Proceedings of the European Transport Conference, Strasbourg France, October 3-5, 2005.

Oum, T, Fu, X, Yu, C. (2005) 'New evidences on airline efficiency and yields: a comparative analysis of North American air carriers its implications'. Transport Policy, Volume 12, Issue 2, pp 153-164

Ortuzar, J de D, Willumsen, L. (2009) Modelling Transport: Fourth Edition. John Wiley \& Sons. Ltd.

Pahwa, A., Feng, X., and \& Lubkeman, D. (2002) Performance evaluation of electric distribution utilities based on Data Envelopment Analysis. IEEE Transactions on Power Systems, 17 (3), 400-5.

Ramanathan, R. (2000) 'A holistic approach to compare energy efficiencies of different transport mode' Energy Policy, Volume 28, Issue 11, pp 743-747

RPA, (2010). Metro North St. Stephen's Green, Airport, Belinstown Updated Detailed Business Case July 2010 [online] Available at: http://www.nationaltransport.ie/news.html [Accessed 20 December 2011]

RPA (2007). Line C1 Final Business Case Version 2.0 [online]. Available at: http://www.transport21.ie/Publications/upload/File/Business_Cases/Luas_Line_C1_B us_Case_Final.pdf [Accessed 15 July 2011]

Sarica, K. \& Or, I. (2007) 'Efficiency assessment of Turkish power plants using data envelopment analysis', Energy, Volume 32, Issue 8, pp 1484-1499.

TCRP (2007), TRB's BRT Practitioner's Guide - Report 118, Transportation Research Board, Washington D.C., 2007

Tudela, A., Akiki, N. \& Cisternas, R. (2006) 'Comparing the output of cost benefit and multi-criteria analysis: An application to urban transport investments'. 
Transportation Research Part A: Policy and Practice, Volume 40, Issue 5, Pages 414423.

Vuuren, D. (2002) 'Optimal pricing in railway passenger transport: theory and practice in The Netherlands'. Transport Policy, Volume 9, Issue 2, Pages 95-106. 


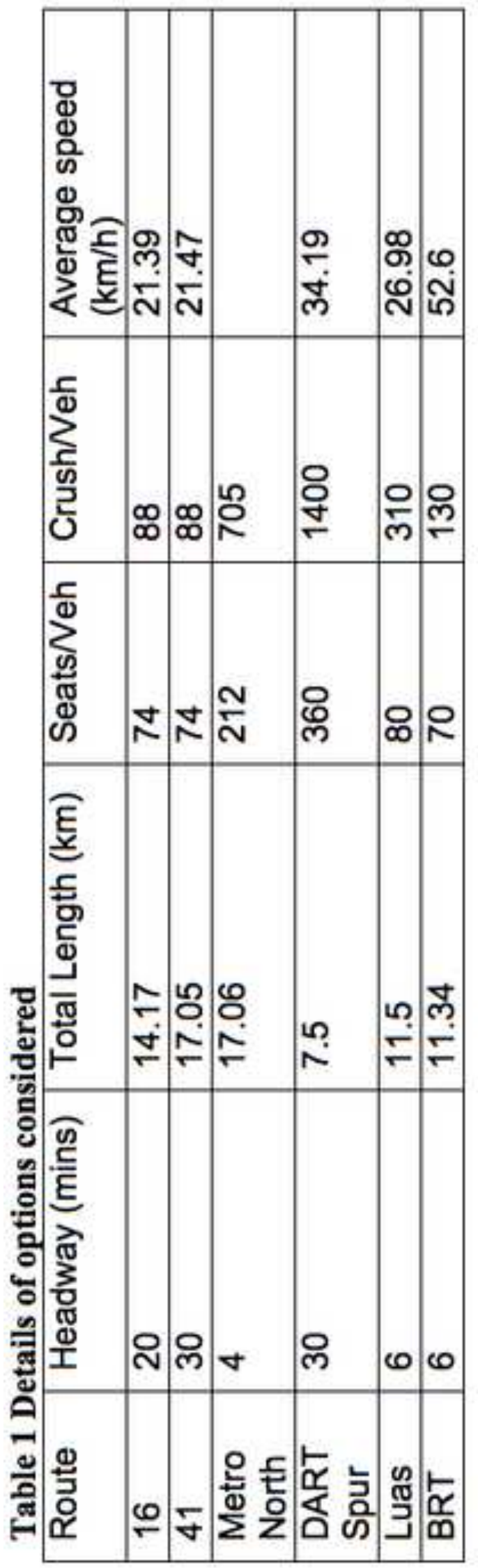




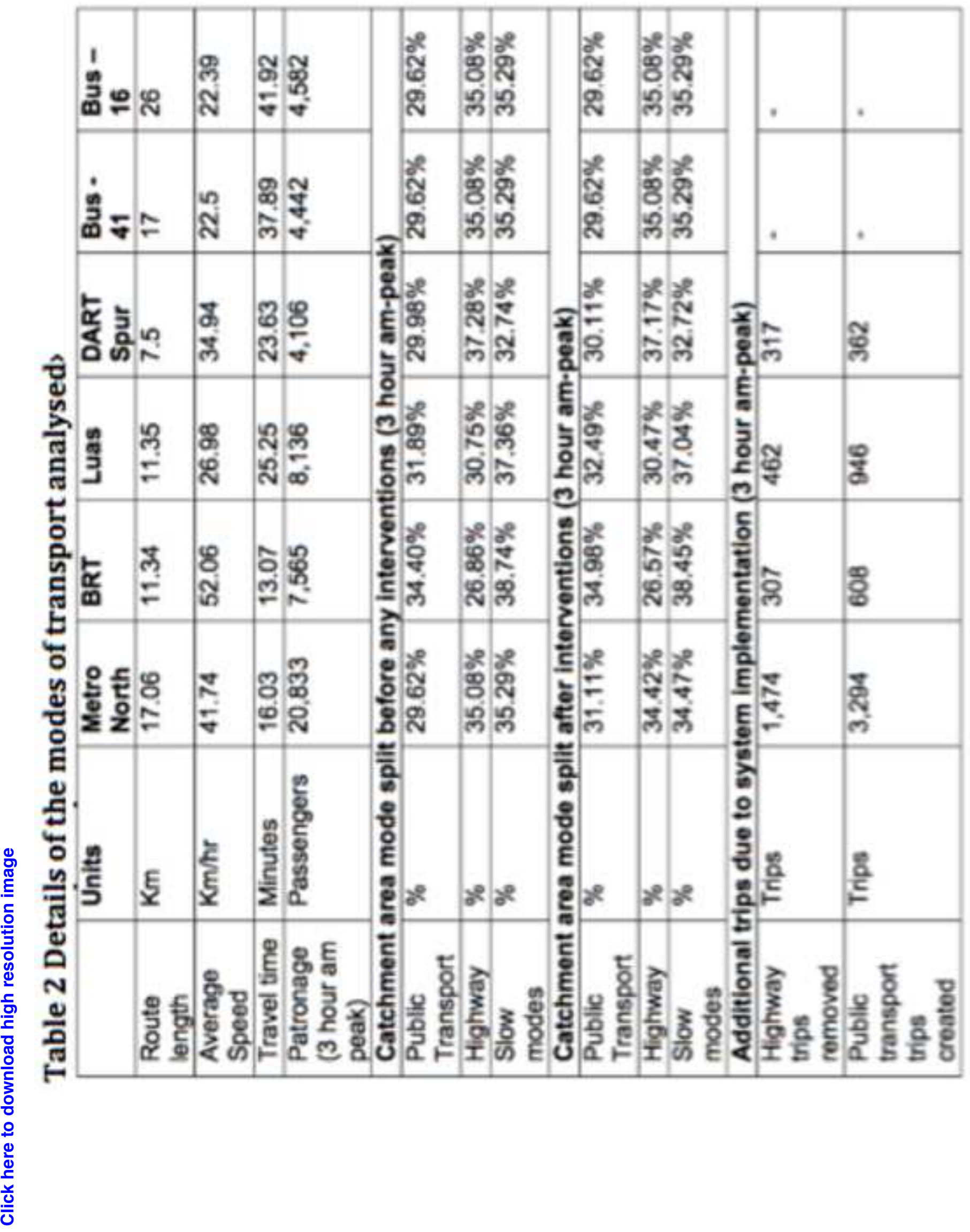


Table 3

Click here to download high resolution image

Table 3: DMU details

\begin{tabular}{|c|c|c|c|c|}
\hline \multicolumn{5}{|c|}{ Travel time saved } \\
\hline DMU & \multicolumn{2}{|c|}{ Travel time (mins) } & \multicolumn{2}{|c|}{$\begin{array}{l}\text { Travel time saved/trip over Bus } \\
\text { route } 16 \text { (mins) }\end{array}$} \\
\hline Bus route 16 & \multicolumn{2}{|l|}{41.92} & \multicolumn{2}{|l|}{$\cdot$} \\
\hline Bus route 41 & \multicolumn{2}{|l|}{37.89} & \multicolumn{2}{|l|}{4.03} \\
\hline Luas & \multicolumn{2}{|l|}{25.25} & \multicolumn{2}{|l|}{16.67} \\
\hline DART Spur & \multicolumn{2}{|l|}{23.63} & \multicolumn{2}{|l|}{18.29} \\
\hline Metro North & \multicolumn{2}{|l|}{16.03} & \multicolumn{2}{|l|}{25.89} \\
\hline BRT & \multicolumn{2}{|l|}{13.07} & \multicolumn{2}{|l|}{28.85} \\
\hline \multicolumn{5}{|c|}{ Patronage } \\
\hline DMU & \multicolumn{2}{|c|}{$\begin{array}{l}\text { Patronage }(100,000 \mathrm{~s} \text { of } \\
\text { passenqers) }\end{array}$} & \multicolumn{2}{|c|}{$\begin{array}{l}\text { Yeariy patronage }(100,000 \mathrm{~s} \text { of } \\
\text { passengers) }\end{array}$} \\
\hline Metro North & \multicolumn{2}{|c|}{0.208} & \multicolumn{2}{|l|}{44.76} \\
\hline Luas & \multicolumn{2}{|l|}{0.081} & \multicolumn{2}{|l|}{17.49} \\
\hline BRT & \multicolumn{2}{|l|}{0.075} & \multicolumn{2}{|l|}{16.27} \\
\hline Bus route 16 & \multicolumn{2}{|l|}{0.048} & \multicolumn{2}{|l|}{9.85} \\
\hline Bus route 41 & \multicolumn{2}{|l|}{0.044} & 9.55 & \\
\hline DART Spur & 0.041 & & 8.83 & \\
\hline & Number of & ar trips I & hoved & \\
\hline DMU & $\begin{array}{l}\text { Additional car trips } \\
\text { (10,000s of trips) }\end{array}$ & moved & $\begin{array}{l}\text { Annual ca } \\
(10,000 \mathrm{~s} \text { c }\end{array}$ & $\begin{array}{l}\text { trips removed } \\
\text { trips) }\end{array}$ \\
\hline Metro North & 0.15 & & 63.38 & \\
\hline Luas & 0.05 & & 19.87 & \\
\hline DART Spur & 0.03 & & 13.63 & \\
\hline BRT & 0.03 & & 13.20 & \\
\hline Bus route 16 & - & & - & \\
\hline Bus route 41 & - & & - & \\
\hline & $\mathbf{C a}$ & ital cost & & \\
\hline & Capital cost ( $\epsilon$ million & & $\begin{array}{l}\text { Capital co } \\
\text { millions) }\end{array}$ & discounted to $2002(€$ \\
\hline Metro North & 62,500 & & $€ 1,756$ & \\
\hline Luas & $€ 363$ & & $€ 276$ & \\
\hline DART Spur & $€ 200$ & & $€ 140$ & \\
\hline BRT & $€ 61$ & & $€ 57$ & \\
\hline Bus route 16 & - & & - & \\
\hline Bus route 41 & $\cdot$ & & - & \\
\hline & & Costs & & \\
\hline & $\begin{array}{l}\text { O\&M cost } / \mathrm{km} / \text { year } \\
(€ 2006)\end{array}$ & $\begin{array}{l}\text { O\&M C } \\
\text { discou }\end{array}$ & $\begin{array}{l}\text { year } \\
d 2002 \text { Es }\end{array}$ & $\begin{array}{l}\text { O\&M cost/year } \\
\text { discounted } 2002 \text { Es }\end{array}$ \\
\hline Bus route 16 & $€ 17,940,000$ & $€ 15,33$ & & $€ 460,055,616$ \\
\hline Metro North & $€ 12,965,000$ & 611,08 & & $€ 332,491,477$ \\
\hline BRT & $€ 12,474,000$ & 610,66 & & $6319,884,824$ \\
\hline Bus route 41 & $€ 11730,000$ & $€ 10,02$ & & $€ 300,805,595$ \\
\hline Luas & $€ 11,577,00$ & $\in 9,896$. & & $€ 296,882,044$ \\
\hline DART Spur & $€ 5,700,000$ & $€ 4,827$ & & $€ 146,171,517$ \\
\hline
\end{tabular}




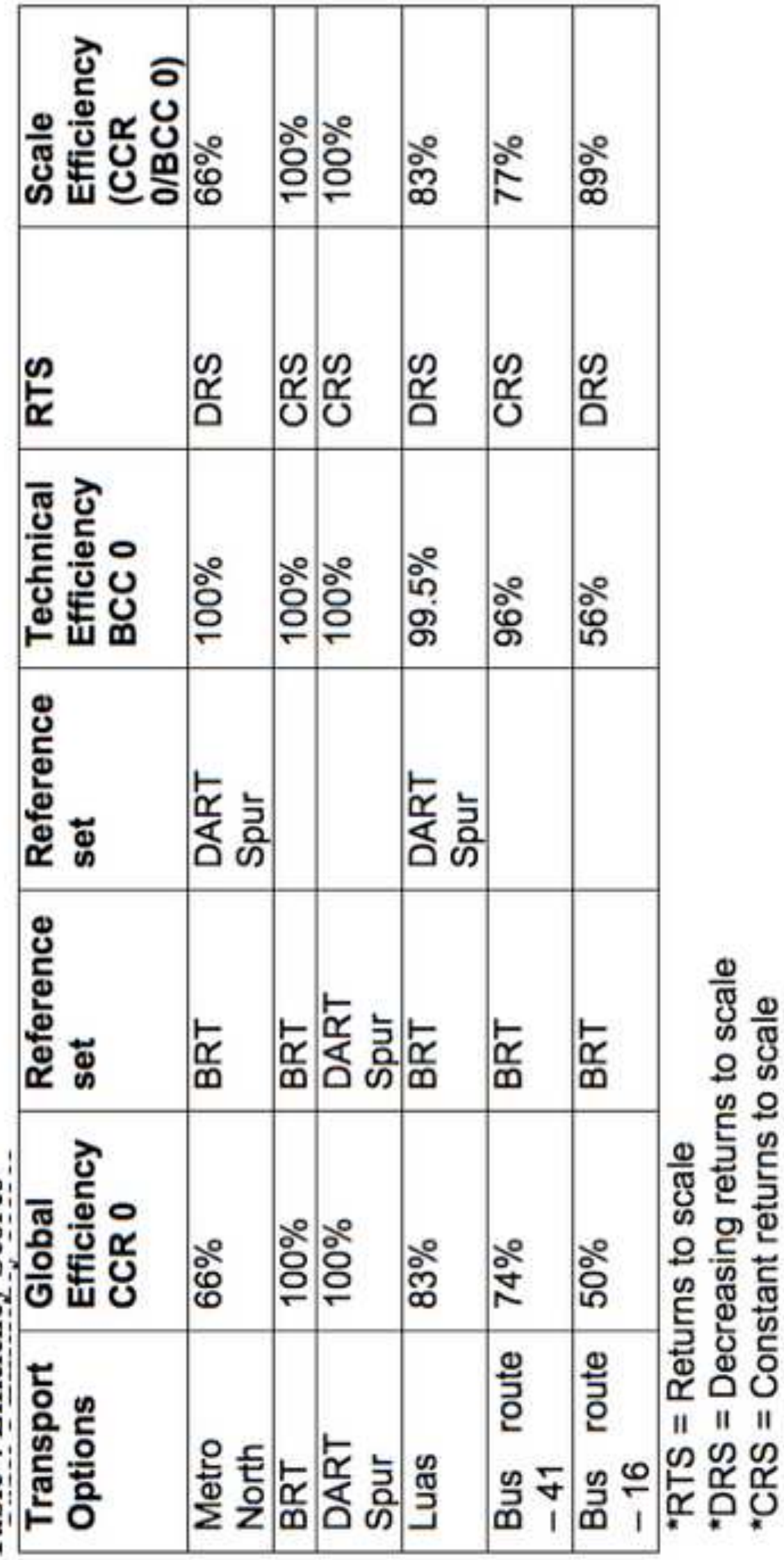




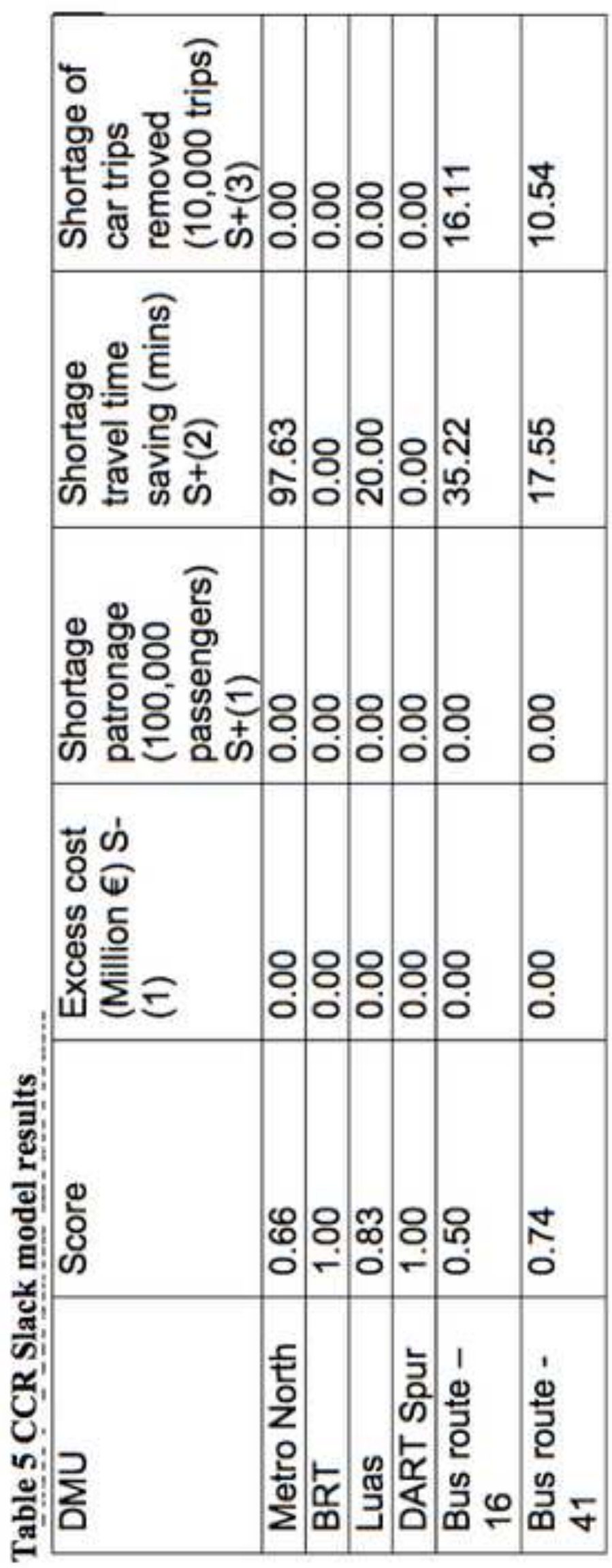

10

高 


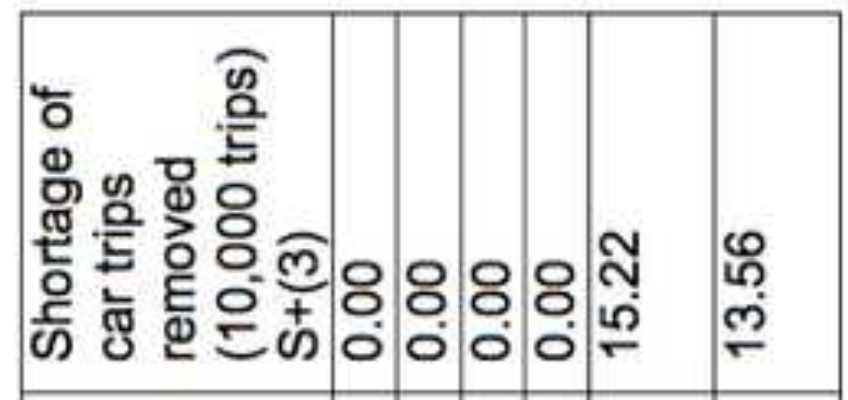




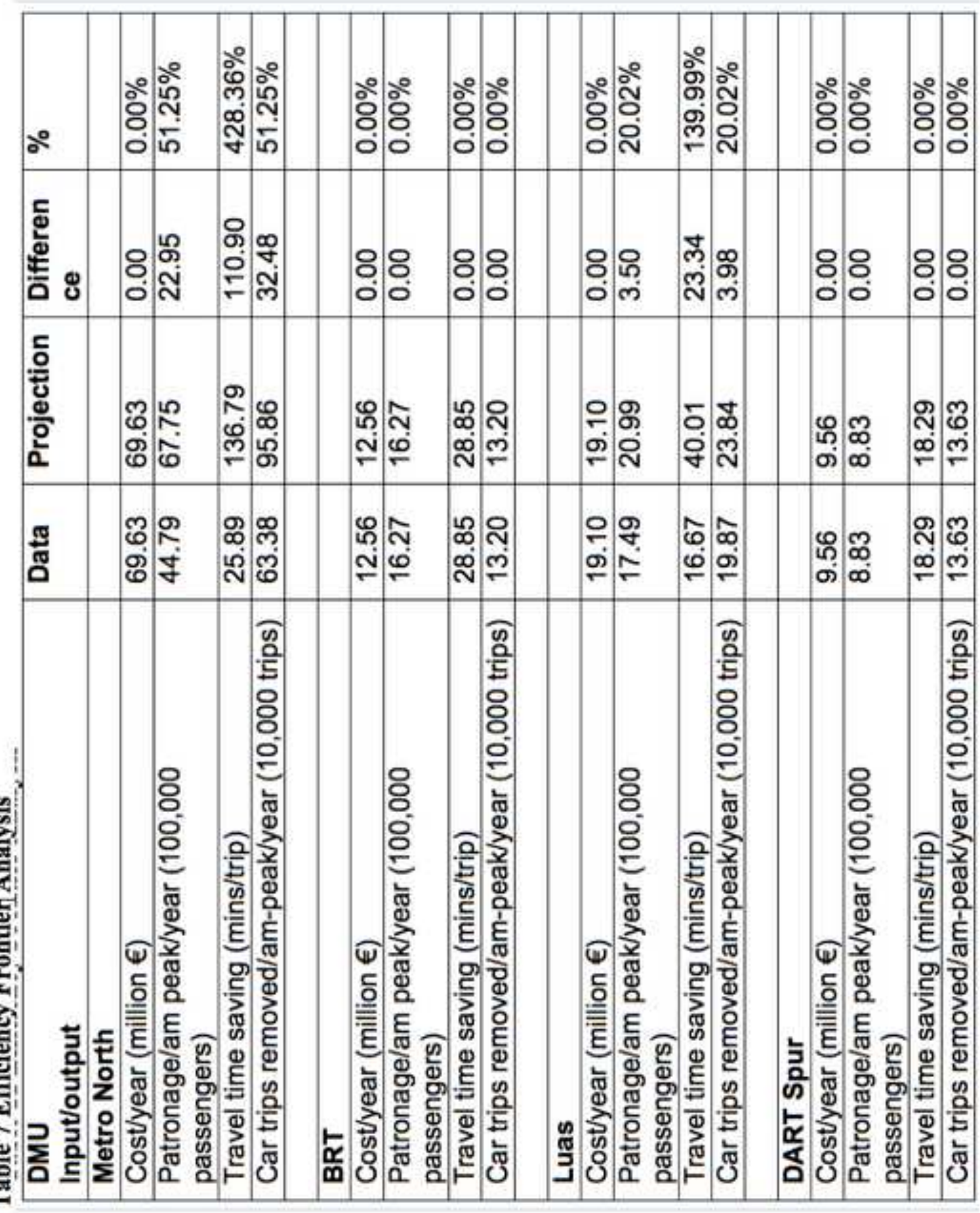

ก

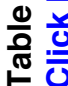




\begin{tabular}{|c|c|c|c|c|c|c|}
\hline$\frac{\stackrel{2}{3}}{\text { के }}$ & 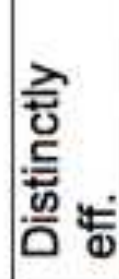 & 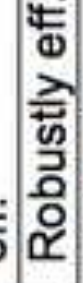 & 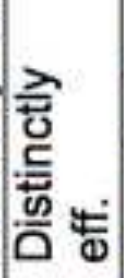 & 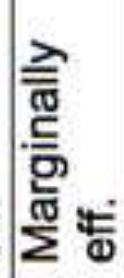 & 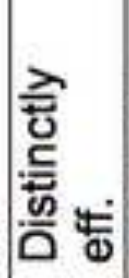 & 章 \\
\hline 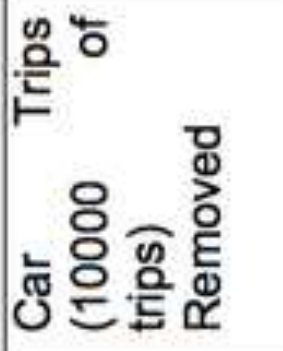 & $\begin{array}{l}\text { g } \\
\text { பे }\end{array}$ & 8 & $\frac{R}{0}$ & $\begin{array}{l}\text { ֻ } \\
0\end{array}$ & 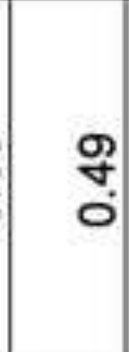 & $\stackrel{M}{O}$ \\
\hline 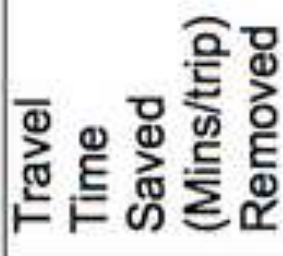 & 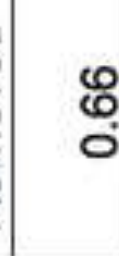 & 8 & $\begin{array}{l}\mathscr{2} \\
\infty \\
0\end{array}$ & $\stackrel{8}{\circ}$ & ণ্ণ & $\stackrel{M}{0}$ \\
\hline 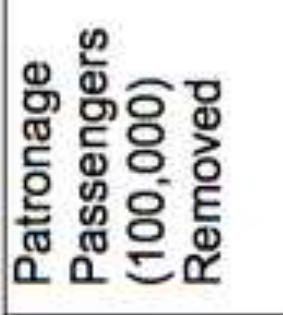 & 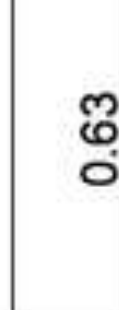 & 8 & $\underset{0}{N}$ & $\stackrel{\text { O }}{-}$ & $\frac{1}{0}$ & ֻூ \\
\hline 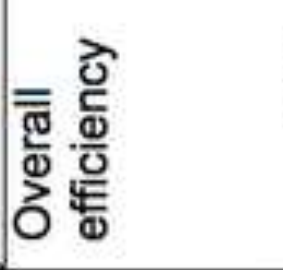 & $\ddot{~}$ & סִ & 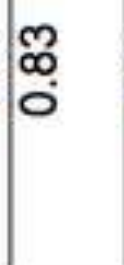 & $\stackrel{8}{\longrightarrow}$ & 各 & $\frac{N}{\tilde{0}}$ \\
\hline 突恋 & $\begin{array}{l}\text { 든 } \\
\text { 은 } \\
\text { 음 } \\
\text { ¿ }\end{array}$ & $\frac{\mathfrak{\alpha}}{\infty}$ & 弯 & $\begin{array}{l}\text { 늠 } \\
\text { के } \\
\text { 듐 }\end{array}$ & 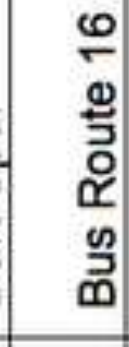 & 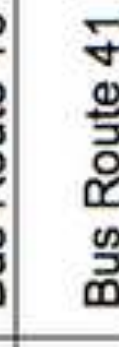 \\
\hline 0 & - & $\sim$ & m & 寸 & 100 & $\omega$ \\
\hline
\end{tabular}




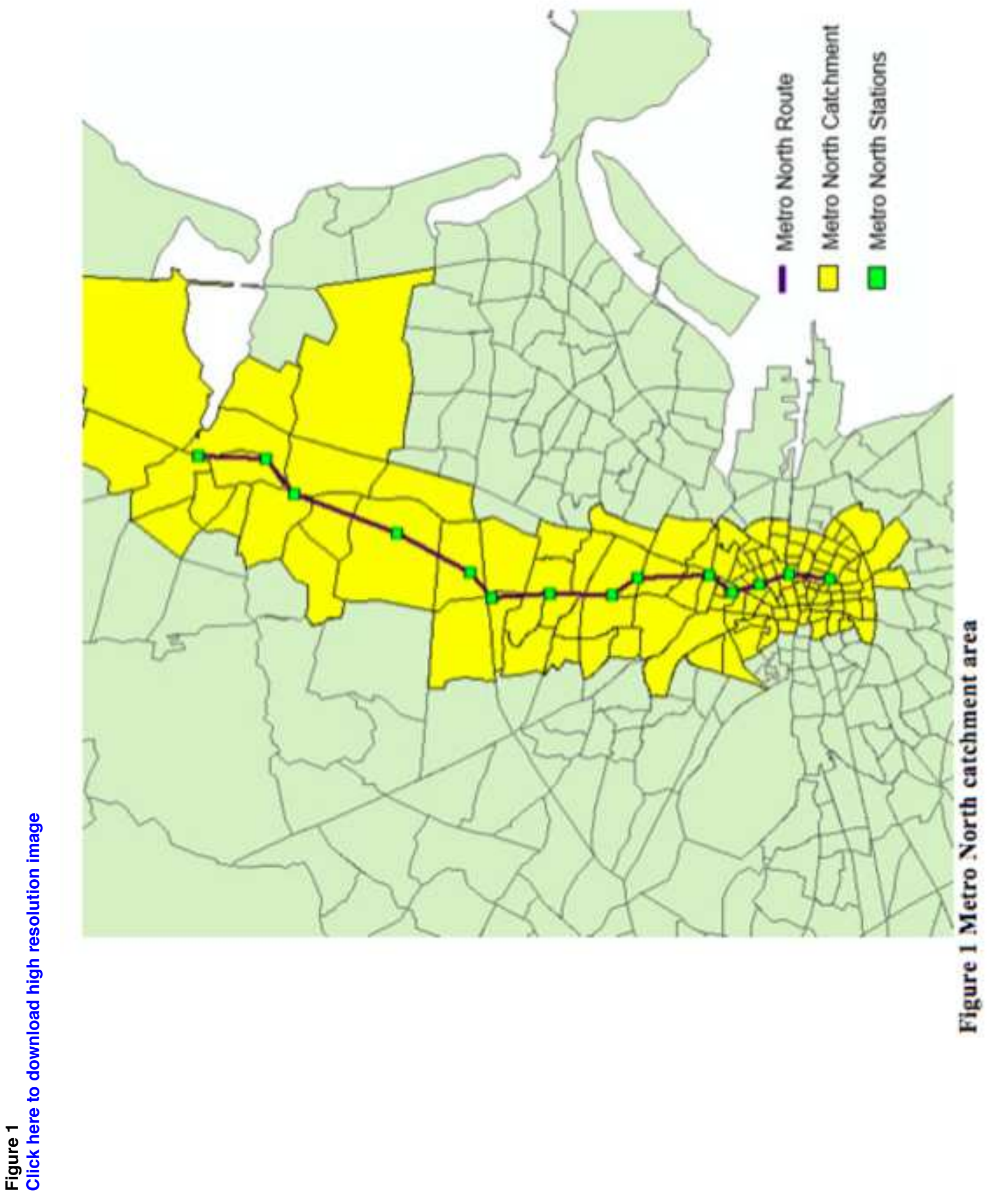




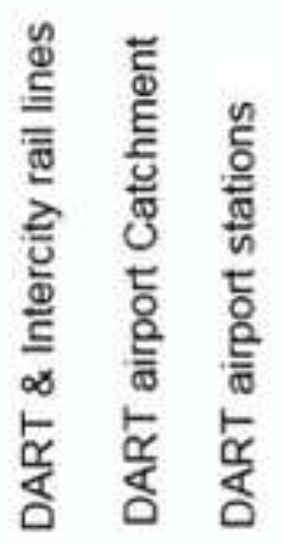

I $\square$ •

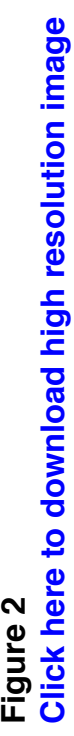
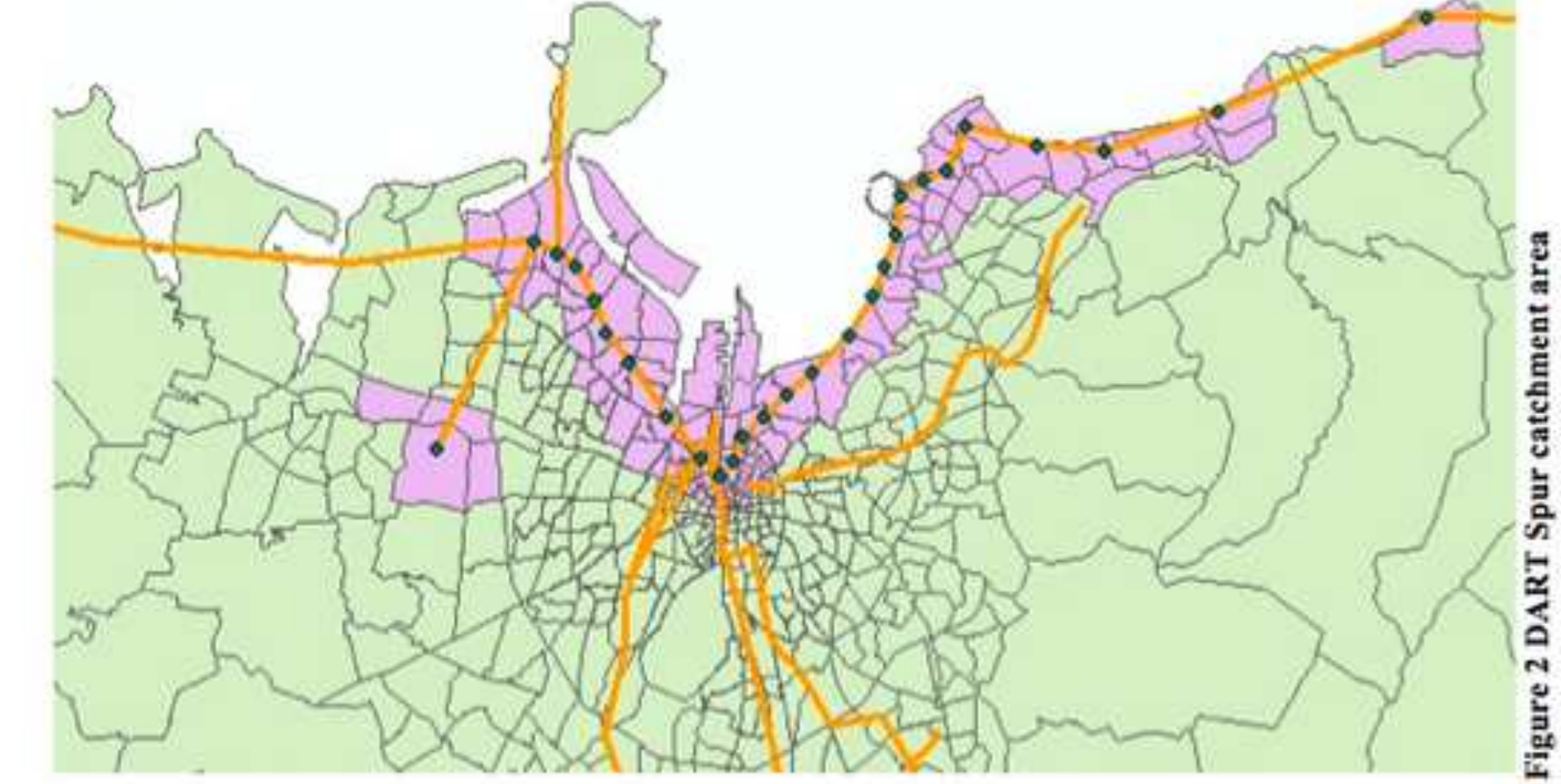

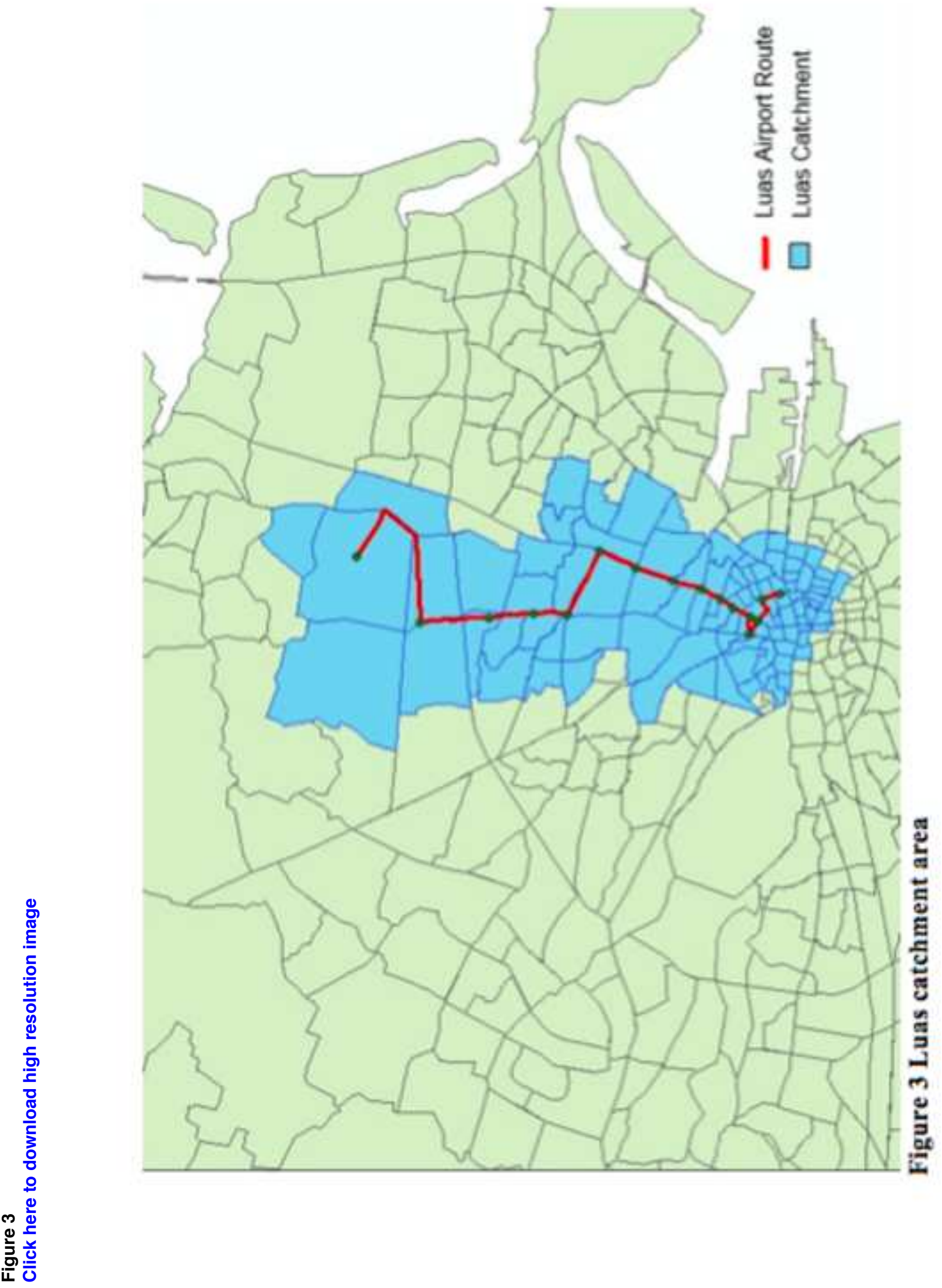


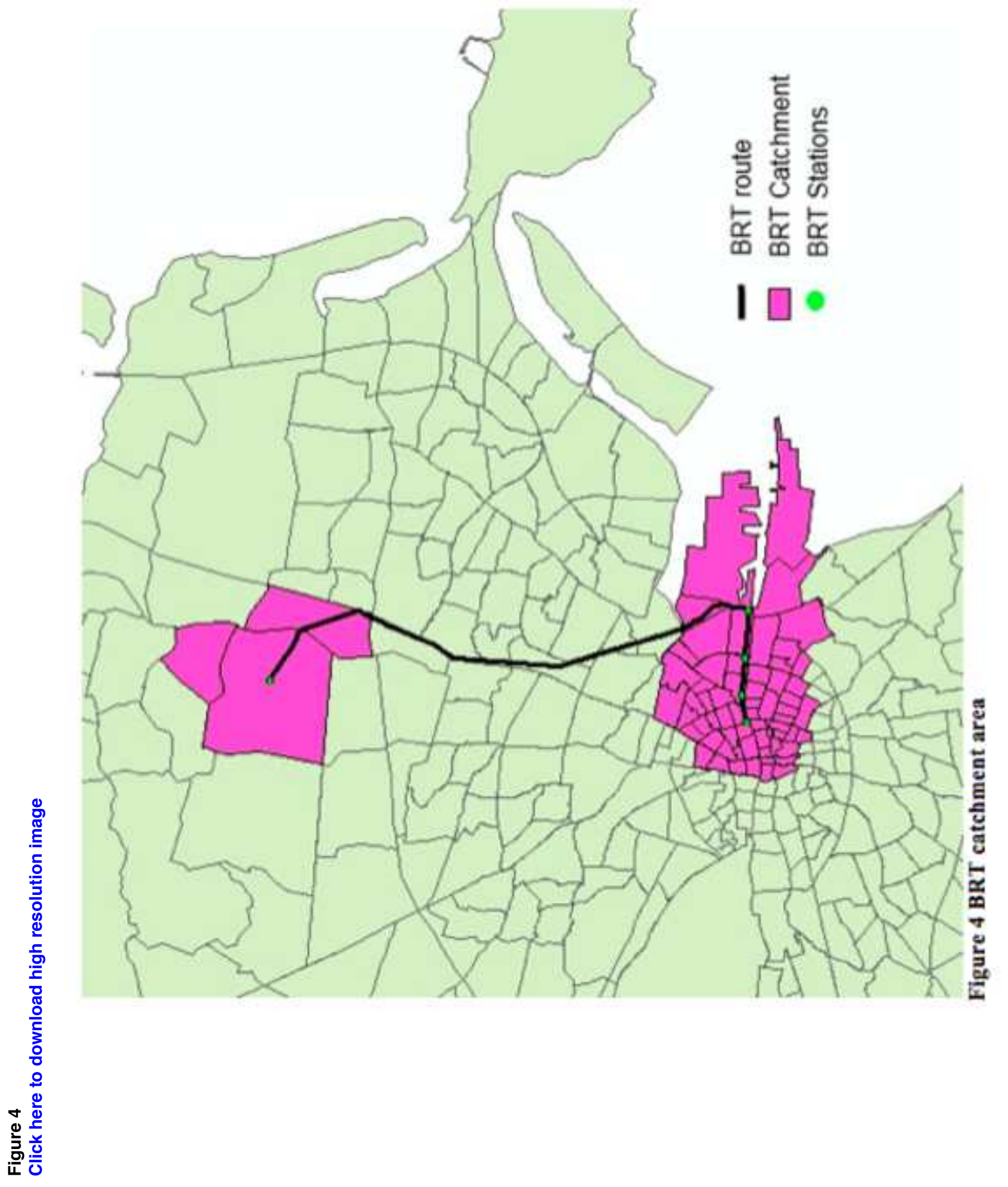

